Geopolítica(s) Revista de estudios sobre espacio y poder ISSN: 2172-3958

\title{
Irlanda libre (y otros textos) $)^{1}$
}

\author{
Plácido Castro
}

Publicados originalmente en 1932, 1927 y 1933

Resumen. Los tres textos seleccionados ilustran algunos de los elementos fundamentales en el pensamiento de Plácido Castro. El primero de ellos versa sobre Irlanda, la nación que para los galeguistas de la época era el espejo en el que mirarse. Para el autor, la integración de Irlanda en la Commonweatlh asegura el disfrute de sus libertades, al tiempo que se beneficia de ventajas comerciales o de la seguridad que le ofrece el Imperio. No obstante, cuando entra en juego el factor sentimental (el deber de los diputados irlandeses de jurar fidelidad a la corona británica) se pone de relevancia la fuerza del nacionalismo. En el segundo, además de Irlanda, el autor se refiere a Escocia y Gales como naciones celtas, hermanas en este sentido de Galicia. El celtismo, otro tema recurrente en el galeguismo, perviviría en el pueblo inculto, verdadero garante de las esencias nacionales. Por último, el tercer artículo da cuenta de la intervención de Castro en representación del Partido Galeguista en el IX Congreso de nacionalidades europeas, celebrado en Berna en 1933. Este momento ha venido a considerarse clave en el reconocimiento internacional de Galicia.

Palabras clave: Galicia; Irlanda; nación; celtismo; nacionalismo.

\section{[en] Free Ireland (and other texts)}

\begin{abstract}
This paper seeks to illuminate essential aspects in Plácido Castro's thinking by looking at three of his key texts. The first piece deals with Ireland, the mirror of nations to which galeguistas looked at. Ireland's integration in the Commonwealth is regarded positively. Castro interpreted that integration secured the liberties of the Irish and, in turn, provided them with privileged access to the commercial and security structures of the Empire. By contrast, when emotional issues are discussed (for instance, the requirement for Irish MPs to swear allegiance to the British Crown) the force of nationalist claims gains salience. The second text identifies Scotland and Wales, in addition to Ireland, as Galicia's sister nations. The preservation of Celtic identity, another recurrent subject for galeguismo, is attributed to the uneducated people, the true guarantors of national essences. Finally, the third article gives account of Castro's performance at the 9th European Nationalities Conference (Berne, 1933) on behalf of Partido Galeguista - a landmark moment in the international recognition of Galicia.
\end{abstract}

Keywords: Galicia; Ireland; nation; celtism; nationalism.

1 (Nota de la redacción) "Irlanda libre" se publicó originalmente en El Pueblo Gallego, el 10 de abril de 1932; "En torno a un título" en la revista Céltiga (Buenos Aires), núm. 62, el 25 de julio de 1927, y "El IX Congreso de Nacionalidades Europeas: el ingreso de Galicia" apareció en El Pueblo Gallego, el 30 de septiembre de 1933. 


\section{[pt] Irlanda livre (e outros textos)}

Resumo. Os três textos selecionados ilustram alguns dos elementos-chave para o pensamento de Plácido Castro. O primeiro deles é sobre a Irlanda, a nação que foi o espelho no qual olhar-se os galeguistas de época. Para o autor, a integração da Irlanda no Commonweatlh assegura o gozo de suas liberdades, enquanto beneficiam de vantagens comerciais ou a segurança oferecida pelo Império. No entanto, quando entra em jogo o fator sentimental (o dever dos deputados irlandeses de jurar fidelidade para a coroa britânica) coloca-se de relevância a força do nacionalismo. No segundo, além de Irlanda, o autor refere-se à Escócia e país de Gales como nações celtas, irmãs neste sentido da Galiza. O celtismo, outro tema recorrente no galeguismo, previveria no povo inculto, verdadeiro fiador da essência nacional. Finalmente, o terceiro artigo reconta a intervenção de Castro em nome do Partido Galeguista no IX Congresso de nacionalidades europeias, realizado em Berna, em 1933. Este momento chegou a ser considerado a chave para o reconhecimento internacional da Galiza.

Palavras-chave: Galícia; Irlanda; nação; celtismo; nacionalismo.

Sumario. Irlanda libre. En torno a un título. El IX Congreso de Nacionalidades Europeas: el ingreso de Galicia.

Cómo citar: Castro, Plácido (2016) "Irlanda libre (y otros textos)". Geopolítica(s). Revista de estudios sobre espacio y poder, vol. 7, núm. 2, 301-307.

\section{Irlanda libre}

El triunfo de De Valera en las elecciones irlandesas es de una importancia capital en la historia de los movimientos nacionalistas y encierra valiosas enseñanzas tanto para los nacionalistas de todos los países como para los Gobiernos que han de resolver problemas autonomistas.

Una vez más se ha demostrado que en el nacionalismo el sentimiento es el factor más potente, dominando todos los aspectos económicos por importantes que estos sean. Irlanda disfrutaba desde 1921 una independencia prácticamente absoluta y un estado de prosperidad muy satisfactorio en las actuales circunstancias, desde luego más favorable que el de Inglaterra. Sus habitantes gozaban de los privilegios de una doble ciudadanía, irlandesa y británica. El convenio financiero con Inglaterra fue sumamente favorable a Irlanda, que se libró de la terrible carga de la deuda nacional y solo contrajo el compromiso de pagar un número de anualidades, de tres millones de libras, para liquidar los préstamos hechos por el Gobierno británico a los agricultores irlandeses con objeto de que adquiriesen las tierras que trabajaban. Es decir, que Irlanda disfrutaba de todas las ventajas de la independencia, y al mismo tiempo se beneficiaba de su asociación con el Imperio, en cuanto esta asociación suponía que Irlanda obtenía en el Imperio un trato favorable en el terreno arancelario y económico, que sus habitantes eran también ciudadanos de un conjunto de naciones que ocupan la quinta parte del mundo, y que su seguridad nacional estaba garantizada por toda la potencia naval y militar del Imperio Británico. Añádase a todo esto que Irlanda estaba regida por uno de los Gobiernos más activos y eficientes del mundo, el cual ha llevado a cabo transcendentales reformas en la economía del país y cuya labor durante diez años ha sido magnífica en todos los aspectos. 
Sin embargo, se celebraron recientes elecciones y el misticismo patriótico de De Valera triunfó sobre la experiencia y la magnífica historia del Gobierno Cosgrave. El juramento de fidelidad a la corona británica por los diputados -único lazo entre las dos naciones, que no implica sumisión alguna de Irlanda al gobierno inglésfue el punto fundamental que se discutió en las elecciones. Por una fórmula, por un juramento, que en sí no tiene importancia alguna, pero que es el símbolo de un resto de dominación extraña, Irlanda arriesgó su bienestar. No su libertad, puesto que nadie sueña en que Inglaterra imponga su criterio por la fuerza. Pero sí su prosperidad económica y los muchos beneficios que provienen de su asociación con el Imperio, y de los cuales le privaría la hostilidad de Inglaterra. Pero Irlanda sentía, ante todo, la posibilidad de realizar el sueño de Finton Lalov, que resume todo el ideal de De Valera: "Irlanda, dueña de sí misma y de todo lo que contiene, desde la tierra hasta el cielo de Irlanda, para que lo posea el pueblo de Irlanda..." Que absurdo suena al lado de esta aspiración el comentario de Churchill "Irlanda será una entidad sin categoría nacional alguna, ni dentro ni fuera del Imperio". Tan absurdo como la actitud de muchos políticos españoles cuyas preocupaciones acerca de la "soberanía" tanto dificultan la solución de los problemas autonomistas y tan mezquinas parecen al lado del anhelo de libertad de los pueblos que reclaman su autonomía. Como dice el Gobierno irlandés, el pueblo ve en el juramento una cosa intolerable, una reliquia del medievalismo. Quiere mantener relaciones de cordial amistad con la Gran Bretaña, pero no cree posible esa cordialidad, ni el establecimiento de la verdadera paz de Irlanda, hasta que el juramento desaparezca. Está dispuesto a transigir, a negociar acerca de las anualidades que paga a Inglaterra. Pero en el aspecto moral del juramento adopta una posición de intransigencia.

La actitud de Inglaterra, si aceptamos como representativo el criterio del Times, es que si los irlandeses quieren ser extranjeros nadie puede impedírselo, y hay que aceptar la nueva situación, limitándose a protestar contra la rotura de un pacto solemne, y a privar a Irlanda de las ventajas que disfruta como componente de la Comunidad de Naciones Británicas. Podemos, pues, considerar como conseguido ese nuevo triunfo en la historia del nacionalismo irlandés. Luego solo le quedará el paso definitivo que será la transformación del cargo de gobernador general —nombrado actualmente por el rey a propuesta del Gobierno de Irlanda, y que en la práctica desempeña las funciones de un presidente de la república- hasta convertirlo en un verdadero presidente elegido por el pueblo irlandés o por su Parlamento. Esta será la etapa final en el proceso de la liberación de Irlanda.

Los nacionalismos pueden seguir dos cursos, según el criterio de los Gobiernos centralistas contra los cuales se alzan. La autonomía concedida a tiempo puede detener el proceso de disgregación y evitar la separación completa. Inglaterra hubiera conservado su "soberanía" sobre Irlanda de haberle concedido la categoría de dominio antes de la guerra, cosa que impidieron los conservadores reaccionarios. En 1921 ya era tarde y ya había corrido demasiada sangre. Inglaterra perdió un trozo más de su imperio por no haber sabido ceder a tiempo.

La tardanza en las concesiones o la falta de generosidad fortalecen el nacionalismo y aseguran su triunfo completo. Los estadistas ingleses ya habrán aprendido esta lección. Ojalá la tengan en cuenta los políticos españoles que prefieren regatear a ser generosos... 
De Valera triunfa en Irlanda. El problema de Malta es cada vez más serio. En Natal se pide la separación de la Unión surafricana. El día de su patrón San David, los galeses indignados por la actitud de un ministro incomprensivo que se negó a que ondeara el legendario dragón céltico sobre el castillo de Carnavón, destrozaron la bandera británica y la sustituyeron por la de su patria. En Escocia el nacionalismo empieza a intervenir en la política y, aunque derrotado, acaba de obtener más de cinco mil votos en una elección parcial. Y finalmente leemos en estos días la noticia de que Filipinas va camino de obtener un grado de autonomía. He aquí datos más que suficientes para oponer a los argumentos de quienes pretenden que el nacionalismo es una cosa anticuada y que los nacionalistas marchamos contra la corriente del mundo actual.

\section{En torno a un título}

Al escribir unas líneas para una revista que se publica en Buenos Aires y que se titula Céltiga, lo primero que surge en el ánimo es un sentimiento de alegría, al pensar que ese título tan significativo ha atravesado el Atlántico, el océano que constituye una parte tan esencial de la vida de los celtas del occidente de Europa. Es un rasgo revelador de la fuerza del espíritu tradicional de los celtas el hecho de que los gallegos de Buenos Aires hayan escogido precisamente ese nombre para su revista de tantos como podían ocurrírsele. Preocupados inevitablemente en su vida cotidiana con el comercio y la industria, con las cosas materiales de la vida, buscaron sin embargo como emblema de sus ideales la palabra que expresa más intensamente la sensibilidad, la espiritualidad, la imaginación. El alejamiento no ha conseguido cambiar la manera de ser de estos gallegos emigrados, del mismo modo que el transcurso de los siglos no ha podido modificar las características de la raza gallega.

Es para mí uno de los fenómenos más notables de la historia la persistencia del espíritu céltico en las regiones del extremo occidental de Europa. Se explica hasta cierto punto en Irlanda, país aislado, que no sufrió la invasión romana y que jamás ha perdido el contacto con su antigua civilización. Poseía ya cuando fue invadida por Inglaterra una alta cultura céltica, una literatura considerable, una valiosa tradición artística, todos los elementos de una nacionalidad bien definida. La dominación inglesa se limitó durante largos años a una zona pequeña alrededor de Dublín, y cuando se extendió a todo el país tuvo siempre en frente una fuerte cultura nacional. En Gales también contribuyeron muchos factores a la conservación del celtismo. La influencia romana no fue prolongada y cuando los romanos se retiraron ante el avance de los anglos y de los sajones, volvió a convertirse Gales en una nación céltica, que perduró hasta la invasión inglesa en la Edad Media. La Iglesia Céltica fue otro poderoso agente que tuvo igual efecto. Escocia, nación también apartada, se mantuvo completamente independiente de Inglaterra hasta principios del siglo diecisiete, en que se unieron las coronas de los dos países, pero la verdadera unión de los reinos no se llevó a cabo hasta el siglo dieciocho. En el siglo dieciséis aún era Escocia no solo una nación independiente sino en muchas ocasiones un serio rival de Inglaterra. Aún hoy conserva su independencia en muchas esferas de su vida y tiene un sentido nacionalista y un orgullo patriótico más fuerte 
que los de la misma Inglaterra. Además de estos factores, la política inglesa nunca fue centralista, y el estado ha intervenido siempre lo menos posible en la vida de los ciudadanos. Hoy procura precisamente estimular el amor a lo propio de cada nación británica para fortalecer la verdadera unión nacional. En fin, en todos los países célticos de las Islas Británicas la supervivencia del idioma, la existencia de una literatura céltica y muchas otras causas tienden a hacer comprensible las diversas formas del nacionalismo céltico después de siglos de lucha con civilizaciones más potentes que la suya.

Pero en Galicia las circunstancias han sido incomparablemente más adversas. La dominación romana fue más completa y prolongada. El idioma celta desapareció en una época remota y no queda de él ni el recuerdo. Las invasiones góticas trajeron nuevas influencias extrañas. La religión ha tenido una tendencia universalizadora y no ha creado una iglesia céltica, nacional, como en los países del norte. La independencia de Galicia fue de corta duración y los gobiernos extraños desde los tiempos de los Reyes Católicos han tenido por ideal la unidad española, unidad entendida a su manera superficial. Nuestra literatura no mantuvo la continuidad espiritual de Galicia pues dejó de existir durante siglos, y solo volvió a resurgir en tiempos comparativamente recientes. Y sin embargo, aunque sería natural el más completo olvido del celtismo, cuando el nacionalismo gallego quiso encontrar su inspiración ideológica la fue a buscar a través de dos mil años de historia. Volvió espiritualmente a aquellos tiempos en que los romanos aún no nos habían impuesto su cultura y sus métodos de gobierno. La única influencia favorable a la conservación del celtismo fue la tradición popular. El pueblo inculto demostró un juicio más certero, un sentido intuitivo de la realidad más acertado que el de las gentes educadas.

Todos los pueblos célticos conservan un recuerdo racial, una tradición popular de tiempos remotos y felices. Sea o no injustificado este recuerdo, demuestra que ninguna cultura posterior ha satisfecho a los celtas. Después de cientos de años hemos tenido que volver al pueblo para buscar la inspiración nacional y salvar lo que aún queda del alma de la raza. En todo caso, mirando a la historia, el fenómeno del renacimiento céltico es bien sorprendente, y en Galicia más que en ninguna parte.

Cuando comencé este articulo pensaba hablar de la influencia de los celtas en la vida inglesa, de la predominancia de sus estadistas en la política británica, y la de sus artistas y escritores en la cultura de la nación, cuya literatura encuentra precisamente en los elementos célticos la base de su grandeza. Pensaba aludir también a la significación en la política norteamericana, y hasta en la internacional de los irlandeses de los Estados Unidos, y de su importante papel en la lucha de Irlanda por la intendencia y en la actual política interna el Estado Libre de Irlanda. La situación de estos irlandeses emigrados tiene muchos puntos de comparación con la de los gallegos de América, y del estudio de su actuación podrían sacarse interesantes deducciones. Pero el tópico requiere demasiado espacio y no deja de ser algo delicado. Solo puedo señalar estos diversos hechos como muestras de la importancia del celtismo en la actualidad política y cultural.

Acaso esté llamado el celtismo a desempeñar un papel decisivo en el desarrollo de la cultural mundial. Tiene muchas de las cualidades cuya ausencia es la causa fundamental del actual desequilibrio del mundo. Puede ser socialmente un freno 
contra el materialismo que es una de las amenazadas más serias que se nos presentan, y cuanto más se estudia la producción artística actual más evidente se hace la necesidad de la delicadez, de la fantasía y del ensueño de los celtas para sacaros de la desorientación que padecemos. Puede librarnos de los dos extremos (que hoy dominan casi todo el arte), de la extravagancia incoherente y del realismo vulgar.

¿Sería ilusión pensar que si el celtismo ha sobrevivido casi milagrosamente, si hoy renace con nueva pujanza, es porque tiene esta alta misión cultural que cumplir? No debemos perder de vista estos aspectos más amplios del nacionalismo, aunque lo esencial sea su influencia dentro de cada país de la raza celta. No podrá ejercer una influencia mundial sin hallar primero su plena realización dentro de los núcleos célticos. Es un camino indirecto, pero es el único seguro.

Y el título de la revista Céltiga de Buenos Aires, es un símbolo del cumplimento de esas dos misiones del celtismo: intensificar el sentimiento céltico entre los celtas y llevar al mismo tiempo su espíritu a través de los mares.

\section{El IX Congreso de Nacionalidades Europeas: el ingreso de Galicia}

Por primera vez en su historia, Galicia ha concurrido con personalidad propia a un Congreso internacional. Ha sometido a la consideración de un organismo adjunto a la Sociedad de Naciones - formado por representantes de casi todos los pueblos o minorías que no hallan salvaguardados sus más íntimos sentimientos e intereses bajo el régimen oficial del estado en que viven - un documento en el cual se hacen constar las circunstancias que justifican el derecho de Galicia a ser considerada como una nacionalidad. Los informes recogidos previamente por la Secretaría del Congreso durante una visita a nuestra tierra confirmaban la tesis nacionalista y probaban a satisfacción del Congreso que no se hablaba de un movimiento surgido de la imaginación y el idealismo de unos cuantos soñadores, sino de un hecho real e importante.

Por esa razón fue acogida Galicia en el Congreso de Nacionalidades Europeas y se admitió la declaración presentada por su delegación, que dice:

El Partido Galeguista, partido nacional de los gallegos, representando en el Parlamento español por los diputados Otero Pedrayo, Castelao y Suárez Picallo, declara solemnemente al participar una delegación gallega en el IX Congreso de Nacionalidades Europeas, basándose sobre el rapport sometido a la consideración del Secretario General de dicho Congreso, que el pueblo de Galicia, que cuenta más de dos millones de almas y habita la totalidad del territorio de Galicia, es una nación bien definida, que se diferencia claramente de los otros pueblos que habitan España. Su origen, su historia, su idioma y sus costumbres justifican esta diferencia de una manera absoluta.

Al hacer constar ante la opinión pública estos hechos incontestables el partido nacional de los gallegos proclama el derecho innegable del pueblo gallego a disponer de sí mismo. El pueblo gallego reclama la plena libertad del empleo de su idioma materno, especialmente en la instrucción. Reivindica igualmente el respeto de sus costumbres y pide la implantación de la más amplia autonomía posible, por exigirla sus intereses económicos y culturales. 
Galicia desea vivir en buenas relaciones con las otras nacionalidades de España y quiere colaborar con ellas para la reglamentación de todas las cuestiones de interés común. Es evidente que no opone ningún obstáculo a la realización de un ideal federal, cualquiera que sea su amplitud.

El partido nota con satisfacción que una unidad de apreciación se ha establecido ya entre gallegos, catalanes y vascos, que, por otra parte, ya se había realizado con la fundación de una organización llamada "Galeuzca", que coordina los movimientos nacionales de Galicia, Euzkadi y Cataluña.

Señalamos también la cordial bienvenida dispensada a la delegación gallega en el discurso inaugural del presidente doctor Josip Wilfan, eminente jurisconsulto de Trieste, ex diputado esloveno en el Parlamento italiano, cuyas afectuosas palabras fueron recogidas por la Prensa europea. Diremos igualmente, antes de finalizar esta primera crónica, que la delegación gallega acompañó al Comité Permanente del Congreso en su visita a M. Mowinchel, presidente del Consejo de la Sociedad de Naciones, y escuchó de labios del primer ministro noruego frases de simpatía hacia los movimientos que luchan por mantener y salvar las culturas y el espíritu de las nacionalidades. No podía ser otro el criterio del representante de una pequeña patria como Noruega, ni el del político que contribuyó señaladamente a la separación de Suecia y Noruega. Lástima que esta admirable nación defensora de los derechos de las nacionalidades, deje este año de pertenecer al Consejo de la Sociedad de Naciones.

Y nada más, en este primer artículo, que reseña la cordial acogida encontrada en todas partes, el genuino interés que despertó la incorporación del nacionalismo gallego a la vida europea y el reconocimiento hacia la nación suiza, que puso el edificio de su Parlamento a disposición del Congreso, y cuyo presidente M. Motta recibió con afectuosas palabras a los delegados.

Expuestos estos hechos de fundamental interés para Galicia, en otras crónicas se dará una impresión del desarrollo de las discusiones del pasado congreso y se estudiará la significación que para Galicia tiene la adhesión de nuestro movimiento nacionalista a una de las organizaciones más interesante de la vida internacional de Europa. 